\title{
Development of stable transgenic maize plants tolerant for drought by manipulating ABA signaling through Agrobacterium- mediated transformation
}

Sridevi Muppala ${ }^{1,2}$, Pavan Kumar Gudlavalleti ${ }^{1 *}$ D, Kodandarami Reddy Malireddy ${ }^{3}$, Sateesh Kumar Puligundla ${ }^{1}$ and Premalatha Dasari ${ }^{2}$

\begin{abstract}
Background: In crop plants, to cope up with the demand of food for rising population, revolutionary crop improvement programmes are being implemented for higher and higher yields. Abiotic stress, especially at flowering stage, causes drastic effect on yield in plants. Deforestation and urbanization made the water table very low and changed the climate which led to untimely and unforeseen rains which affect the yield of a crop through stress, both by lack of water as well as water logging (abiotic stress). Development of tolerant plants through breeding is a time-consuming programme and does not perform well in normal conditions. Development of stresstolerant plants through transgenic technology is the better solution. Maize is a major crop used as food and fodder and has the commercial value in ethanol production. Hence, the genes viz., nced (9-cis-epoxycarotenoid dioxygenase) and rpk (receptor-like protein kinase), which play the key roles in the abscisic acid pathway and upstream component in ABA signaling have been transferred into maize plants through Agrobacterium-mediated transformation by optimizing several parameters to obtain maximum frequency of transformation.

Results: Cultures raised from immature embryos of 2-mm size isolated from maize cobs, 12-15 days after pollination, were used for transformation. rpk and nced genes under the control of leaP and salT promoters respectively, cloned using gateway technology, have been introduced into elite maize inbred lines. Maximum frequency of transformation was observed with the callus infected after 20 days of inoculation by using $100 \mu \mathrm{M}$ acetosyringone, 10 min infection time, and 2 days incubation period after co-cultivation resulted in maximum frequency of transformation (6\%) in the NM5884 inbred line. Integration of the genes has been confirmed with molecular characterization by performing PCRs with marker as well as gene-specific primers and through southern hybridization. Physiological and biochemical characterization was done in vitro (artificial stress) and in vivo (pot experiments).
\end{abstract}

Conclusions: Changes in the parameters which affect the transformation frequency yielded maximum frequency of transformation with 20-day-old callus in the NM5884 inbred line. Introducing two or more genes using gateway technology is useful for developing stable transgenic plants with desired characters, abiotic stress tolerance in this study.

Keywords: Abiotic stress, Agrobacterium-mediated transformation, Immature embryo, Inbred line, Maize

\footnotetext{
* Correspondence: dr.gpavankumar@gmail.com

'Department of Biotechnology, Nuziveedu Seeds Limited, Hyderabad,

Telangana 501401, India

Full list of author information is available at the end of the article
}

\section{Springer Open}

(- The Author(s). 2021 Open Access This article is licensed under a Creative Commons Attribution 4.0 International License, which permits use, sharing, adaptation, distribution and reproduction in any medium or format, as long as you give appropriate credit to the original author(s) and the source, provide a link to the Creative Commons licence, and indicate if changes were made. The images or other third party material in this article are included in the article's Creative Commons licence, unless indicated otherwise in a credit line to the material. If material is not included in the article's Creative Commons licence and your intended use is not permitted by statutory regulation or exceeds the permitted use, you will need to obtain permission directly from the copyright holder. To view a copy of this licence, visit http://creativecommons.org/licenses/by/4.0/. 


\section{Background}

Unlike animals, plants are sessile and exposed to different biotic and abiotic stresses, which refers to the conditions imposed externally and cause drastic effect in their growth and development which finally influence the productivity of the plant. Most of the plants and or crops are sensitive to abiotic stresses viz., drought, salinity, temperatures, and other environmental extremes. For compensating such adverse conditions, plants develop unique mechanisms to react with the tough environmental conditions by changing themselves, flexible to adapt the conditions. Several molecular changes occur to control the stress conditions by controlling the mechanisms for abiotic stress tolerance by the activation and regulation of specific stress-related genes. Development of varieties with improved growth under stress conditions is a big challenging task in crop plants. Though the development of drought-resistant plant varieties is the straightforward method, it is not only the time-taking method, but also it may not perform well in the normal conditions. Molecular genetics and biotechnology play an important role to get the resistant plants either by enhancement of native genes or by introducing the resistance genes from the other plant species under the control of stress-induced promoter.

Mostly, under stress conditions, membrane transport and perception systems have critical and essential roles for maintaining the cellular homeostasis. Abiotic stress conditions such as drought induces ABA biosynthesis which initiates the signaling pathways that lead to a number of molecular and cellular responses, among which the best known are the expression of stressrelated genes and stomatal closure. ABA biosynthesis and catabolism are known to be major determinants of endogenous ABA levels in plant cells $[1,2]$. In ABA biosynthesis, 9-cis-epoxycarotenoid dioxygenase (nced) gene encodes a key enzyme which up-regulates endogenous ABA levels in over expressed transgenic plants under drought, thereby leading to lower transpiration rates $[3$, 4]. Over expression of NCED gene resulted in ABA accumulation and increase the drought tolerance in tomato [5], cowpea [6], tobacco [7], peanut [8], rice [9], petunia [10], cotton [11], and Arabidopsis [12].

Stress-inducible genes function not only in protecting cells by producing metabolic proteins, but also in regulating important genes for signal transduction in the stress response $[13,14]$. ABA signal transduction initiates signal perception by ABA receptors and transfer via downstream proteins, which includes protein kinases and phosphatases. Receptor-like protein kinases (RLKs), which are receptors localized on the plasma membrane, play important roles in stress response. Transgenic plants overproducing RPK1 have an increased tolerance to drought stress as well as oxidative stress. It also controls reactive oxygen species' homeostasis and enhances both water and oxidative stress tolerance in Arabidopsis [15].

Maize (Zea mays L.) is the principal crop of the world. Drought causes significant decrease in maize grain yield, especially at sensitive reproductive stage. Agrobacteriummediated genetic transformation is one of the best tools in biotechnology for getting the plants with desired genes. Transgenic maize plants were obtained using different types of explants viz., immature embryos [16], shoot apices [17], and immature embryo-derived calli [18]. Immature embryos were proved to be the most preferred explants for highly efficient transformation. Hence, the present study has been taken up to develop the drought-tolerant maize lines by introducing two genes viz., nced and rpk which play the key role in the ABA pathway by adopting Agrobacterium-mediated transformation.

\section{Methods \\ Plant material}

Commercial maize lines viz., NM74C and NM5884, proprietary elite inbred lines of Nuziveedu Seeds Limited, Hyderabad, were used as a source material. For ensuring the continuous supply of immature embryos (IEs), seeds were sown in 4-5 lines staggeredly with 3-4-day intervals. Strict selfing of the cobs was done.

\section{Agrobacterium strain and construct}

Hyper virulent strain of Agrobacterium tumefaciens, EHA105, containing the gateway vector pMDC99 was used for transformation experiments. This construct contains two genes viz., rpk and nced driven by Lea (Lea P) and SalT (SalT) promoters, respectively. Both the genes were terminated by nopaline synthase (nos) terminator. Hygromycin phosphotransferase gene (hpt II) was used as plant selectable marker (Fig. 1).

\section{Explant preparation}

Immature ears harvested between 12 and 15 days after pollination (DAP) from the field-grown plants were sterilized with $10 \%$ sodium hypochlorite solution $(4 \% \mathrm{w} / \mathrm{v})$ for $15 \mathrm{~min}$, followed by three washes with sterile distilled water for $5 \mathrm{~min}$ each. Young kernels were dissected to isolate the embryos; of which IEs of 2-mm size only used as explants (Fig. 2A).

\section{Infection and co-cultivation of explant}

Single colony picked up from the Agrobacterium cultures plate was inoculated in Luria Bertani broth (LB) liquid culture supplemented with rifampicin and chloramphenicol at a concentration of $25 \mathrm{mg} / \mathrm{L}$ each and kanamycin at $50 \mathrm{mg} / \mathrm{L}$ and incubated at 28 ${ }^{\circ} \mathrm{C}$ by shaking at $200 \mathrm{rpm}$ for overnight until it 


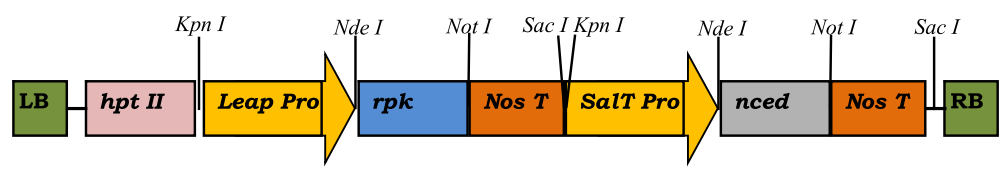

Fig. 1 T-DNA composition of vector used in Agrobacterium-mediated transformation experiments of maize (Zea mays L.) with multi gene construction in single binary Gateway plant transformation vector pMDC99 having rpk (receptor-like protein kinase) and nced (9-cisepoxycarotenoid dioxygenase) genes driven by LeaP and SalT promoters respectively

attains 0.8 optical density (OD). Then it (suspension) was centrifuged at $6000 \mathrm{rpm}$ for $20 \mathrm{~min}$, and the pellet was dissolved in equal volume of infection medium and then used for infecting the explants (IEs) or calli.

\section{Callus induction and regeneration}

Linsmaier and Skoog (LS) media supplemented with a single concentration $(1.5 \mathrm{mg} / \mathrm{L})$ of 2 , 4-dichloro phenoxyacetic acid (2, 4-D) was used in all steps (except regeneration) involved in transformation viz., infection, cocultivation, selection, which was found to be the best concentration in our previous study [19]. LS medium supplemented with 6-benzylaminopurine (BAP) and kinetin each at a concentration of $0.5 \mathrm{mg} / \mathrm{L}$ has been used as regeneration medium.
Selection of transformed E. calli, its regeneration, and rooting

Proliferated calli which showed resistance in two selections against 10 and $12 \mathrm{mg} / \mathrm{L}$ hygromycin respectively were transferred onto the regeneration medium with BAP and Kn each of $0.5 \mathrm{mg} / \mathrm{L}$ by maintaining in light at $26 \pm 1{ }^{\circ} \mathrm{C}$ under $16 / 8$ h. (light/dark) photoperiod. Then the regenerated shoots were transferred onto MS basal medium for elongation and rooting. Profusely rooted plantlets were maintained in cocopeat at an ambient temperature of $28 \pm 1{ }^{\circ} \mathrm{C}$ for primary hardening. After 12 days, the plants were transferred onto the soil in polyhouse.

\section{Characterization of transgenics Molecular characterization}

PCR analysis Genomic DNA was extracted from young leaves of putative transgenic plants along with untransformed plants (control) using the CTAB method [20].
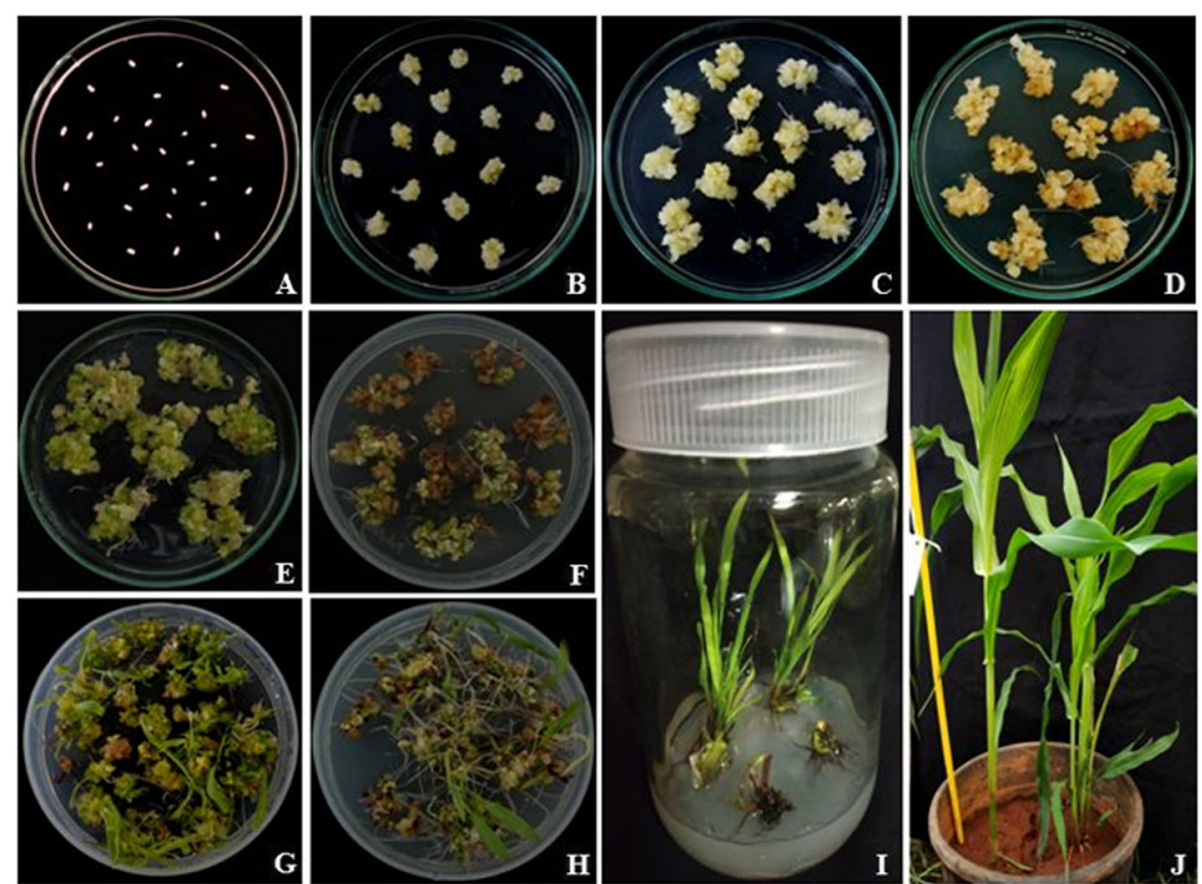

Fig. 2 Different stages of maize cultures from inoculated nascent explants (immature embryo) (A) to fully developed hardened plants transferred into pots grown in poly house (J), after going through different stages of Agrobacterium-mediated transformation viz., co-cultivation (B), selection I (D), selection II (F), regeneration of plantlets $(\mathbf{H})$, and rooting of plantlets (I); cultures without co-cultivation acts as controls at every stage $(\mathbf{C}, \mathbf{E}, \& \mathbf{G})$ 
Specific primers designed for two genes and selectable marker namely, $r p k$, nced, and hptII were used. The primer sequences are forward-5'CGTGGACAGCACAAGACAAC3' and reverse-5' GTCGGAAACCCAGCTAGACA3' for $r p k$ gene, forward-5'GGTTGGTCAGATTCCTTCTTG3' and reverse-5'GACCGTCGATCTTCACTTGG3' for nced gene, and forward-5'CACAATCCCACTATCCTTCGC3' and reverse-5'GCAGTTCG GTTT CAGGCAGGT3' for selectable marker (hygromycin).

Southern hybridization Genomic DNA $(20 \mu \mathrm{g})$ from positive putatives along with control plants were digested with BamHI restriction enzyme overnight at 37 ${ }^{\circ} \mathrm{C}$ in water bath. Then the digested products were separated on $0.8 \%$ agarose gel, and the depurinated gel was transferred to positively charged Hyband-N + Nylon membrane (Amersham Biosciences, UK) by the upward capillary method described by Sambrook and Russel [21]. Then the UV cross-linked Nylon membrane was probed with Alkaphos non-radioactive direct labeling kit (Amersham Biosciences, UK) in the hybridization oven. After washing the membrane with primary and secondary wash buffers, detection reagent was applied to the membrane and finally exposed to an X-ray film. Then the film was developed for copy number enumeration. All the above procedures were followed as per the instruction manual (Amersham Biosciences, UK) supplied along with the kit. Primarily the membrane was probed with nced gene, after exposure, the membrane was stripped and again processed with remaining probes namely $r p k$ and $h p t I I$.

\section{Physiological and biochemical characterization}

$\mathrm{T}_{1}$ plants which were found to be positive for selectable marker as well as two genes were selected (15 plants); five plants each from three elite lines (ET-2-1, ET-2-4, ET-2-5, ET-2-12, ET-2-15, ET-5-2, ET-5-3, ET-5-8, ET5-11, ET-5-14, ET-9-1, ET-9-2, ET-9-7, ET-9-10, ET-918) were characterized physiologically and biochemically, for which ion leakage, lipid peroxidation, proline estimation, and pigment analyses (chlorophyll (Chl)-A, Chl-B, total chlorophyll, and carotenoids) were studied.

Artificial stress by methyl viologen For physiological and biochemical characterization, stress has been induced by treating the leaf disc material with methyl viologen at a concentration of $250 \mu \mathrm{M}$, exposed for $36 \mathrm{~h}$ of dark continuously.

Electrical conductivity for measuring ion leakage Ion leakage studies were done by following the protocol described by Kumari et al. [22]. Leaf discs, treated with methyl viologen, were washed with distilled water, and electrical conductivity (Ei) was recorded. Then the leaf discs were exposed to continuous light for $12 \mathrm{~h}$, and EC (E1) was taken. Finally, the leaf discs were incubated at $100{ }^{\circ} \mathrm{C}$ for $1 \mathrm{~h}$, and then E2 (final EC) was taken after cooling the tubes and ion leakage was calculated by using the standard formulae.

Lipid peroxidation Lipid peroxidation was studied by measuring the MDA content by following the standard protocol described by Heath and Packer [23]. A 5\% TCA (trichloro acetic acid) was used to grind the leaf material and 20\% TCA containing 0.5\% TBA was mixed with supernatant and incubated for $30 \mathrm{~min}$ at $95{ }^{\circ} \mathrm{C}$ in water bath. It was cooled immediately by keeping in ice. OD values of supernatant were taken at $\mathrm{A}_{532}, \mathrm{~A}_{600}$, and $\mathrm{A}_{450}$ for calculating MDA content with standard formula by using $155 / \mathrm{M} / \mathrm{cm}$ extinction coefficient, and the concentration of MDA was expressed in $\mathrm{nM} / \mathrm{gFW}$.

Estimation of proline content Free proline content was estimated by following Bates et al. [24]. Leaf samples $(0.5 \mathrm{~g})$ were homogenized in sulphosalicylic acid (3\% w/ v), and homogenate was filtered through filter paper. After adding the acid, ninhydrin, and glacial acetic acid, the resultant mixture was heated for $1 \mathrm{~h}$ in water bath at $100{ }^{\circ} \mathrm{C}$. Then the reaction was stopped by using an ice bath. The mixture was extracted with toluene, and the absorbance was measured at $\mathrm{A}_{520} \mathrm{~nm}$. Proline concentration was determined using standard curve and expressed as $\mu \mathrm{g} / \mathrm{g}$ tissue.

Chlorophyll (Chl-A, Chl-B, and total) and total carotenoid estimation Standard procedures [25] were used to analyze photosynthetic pigment analyses. Leaf discs (transgenics as well as non-transgenic) were subjected to $36 \mathrm{~h}$ methyl viologen stress and incubated overnight in dark with $5 \mathrm{~mL}$ of DMSO for chlorophyll extraction. Then the extracted chlorophylls were estimated through photometric methods at different wavelengths of $A_{663}, A_{645}$, and $A_{480}$ for chlorophyll-A, chlorophyll-B, total chlorophyll, and total carotenoids. Calculations were done by using standard formulae.

Pot experiment of transgenic maize for drought screening (in vivo) Pot experiment was conducted with three independent transgenic plants (ET-2-3, ET-5-17, and ET-9-14) along with wild-type under severe water deficit condition ( 9 days), and then leaf samples were collected for ABA analysis. After 9 days, plants were recovered by pouring the water equally to all plants.

\section{Hormone (ABA) extraction and analysis}

Standard procedure established by Dobrev and Vankova [26] has been followed. Leaves (100 mg) collected from 
control and transgenic plants subjected to drought stress were ground, by adding $5 \mathrm{~mL}$ of $80 \%$ cold aqueous methanol and kept in dark at $4{ }^{\circ} \mathrm{C}$ overnight. The extract was filtered twice and finally total methanolic extract was dried using $\mathrm{N}_{2}$ gas. The residues were dissolved in 1 $\mathrm{mL}$ of $80 \%$ methanol solution and vortexed. The dissolved samples were filtered and placed in vials by adjusting the volume to $1.5 \mathrm{~mL}$ with the mobile phase for the analysis using a high-performance liquid chromatography (HPLC) system (Waters e2695). Separation was carried out on a Waters Symmetry C18 column (4.6 $\times$ $250 \mathrm{~mm}, 5 \mu \mathrm{m}$ ) by maintaining at $25{ }^{\circ} \mathrm{C}$ with $0.5 \mathrm{~mL} /$ min flow rate. The mobile phase was composed of acetonitrile $(60 \%)$ and $1 \%$ glacial acetic acid $(40 \%)$ and performed in isocratic method. The target component was quantified by the peak areas at the maximum wavelength of $254 \mathrm{~nm}$.

\section{Statistical analysis}

Data obtained on the effects of various parameters on survival frequencies on hygromycin selection regime and physiological and biochemical data obtained from transgenic plants with reference to their control wild type plants were subjected to statistical analyses by following Snedecor and Cochran [27].

\section{Results}

Our in vitro studies in maize [19] revealed that immature embryos (IEs) of 2-mm size isolated 12-15 days after pollination gives high frequency of regeneration, and the larger quantities of embryonic callus (E.callus) from the inbred lines NM74C and NM5884 among the four inbred lines studied. Hence, these two inbred lines which were found to be more regenerative and yielded larger quantities of E.callus have been used in the present study by following in vitro practices adopted in our previous studies viz., Linsmaier and Skoog's (LS) medium [28] supplemented with $1.5 \mathrm{mg} / \mathrm{L} \mathrm{2,} \mathrm{4-D} \mathrm{for}$ callus induction and LS with BAP and $\mathrm{Kn}(0.5 \mathrm{mg} / \mathrm{L}$ each) for regeneration [19].

\section{Influence of callus age on transformation efficiency}

For genetic transformation, initially Agrobacterium infection was given to the explants (Fig. 2A), which was found to be not promising not only for callus growth and survival frequency of callus but also the plantlet regeneration. Most of the embryos did not induce any callus and turned to brown; only few embryos induced primary calli, but plantlets were not generated from them in both the genotypes; hence, the IEs with initiated callus at different time intervals after inoculation viz., after 10, 20, 30, and 40 days have been used for co-cultivation (Table 1). Calli which proliferated from the explants have been subcultured onto the media supplemented with hormones and cefotaxim
(500 mg/L) without antibiotic (hygromycin). After 2 weeks, calli were transferred onto the selection medium I and then to selection medium II (LS medium supplemented with $1.5 \mathrm{mg} / \mathrm{L} \mathrm{2}$, 4-D having 10 and $12 \mathrm{mg} / \mathrm{L}$ hygromycin respectively) with an interval of 2 weeks. The transformed calli survived on the selection medium II, have been transferred onto regeneration medium. Survival frequency of callus was studied at both the selection stages as well as regeneration stage (Table 1). IEs cultured without co-cultivation with Agrobacterium were served as controls throughout the experiment (Fig. 2C, E, G). Survival frequency on selection medium II ranged from 1 to $46 \%$ and regeneration frequency ranged from 1 to $25 \%$ in these genotypes. Maximum survival and regeneration frequencies of 46 and 25 were found in NM5884 inbred line where infection was done after 20 days, and lowest survival $(1 \%)$ and regeneration (1\%) frequencies were observed in NM74C inbred line. Co-cultivation given 20 days after explant inoculation, resulted in maximum survival frequency of callus at subculture as well as both the selection stages (Table 1) (Fig. 2B, D, F). Regeneration frequency has also been found to be maximum in both the inbred lines. Callus growth-i.e., survival frequency at all stages (subculture, selection I and II) - as well as regeneration frequency were found to be increased with increasing time interval of co-cultivation up to 20 days and then decreased with further increase in time in both the inbred lines (Table 1). Among the two inbred lines used, NM5884 resulted in better survival frequency of callus as well as regeneration frequency over the other inbred line NM74C in all time intervals. Variation among these two inbred lines was found to be significant (ANOVA) ( $p=$ 0.05 ) for survival frequency as well as regeneration frequency. But, these two parameters were not found to be significant in any of the inbred lines (within the group variation) $(p<0.05)$.

Though the IEs are mostly affected with Agrobacterium co-cultivation and influenced the survival frequency of explants, calli growth and also regeneration, in order to enhance the survival frequency at every step to achieve maximum frequency of genetic transformation, several parameters involved in the process of transformation have been considered and further studied using the inbred line NM5884, which was found to be more suitable when compared with NM74C.

\section{Optimization of various factors affecting plant transformation}

Influence of bacterial population in co-cultivation

Population of bacteria-i.e., concentration of Agrobacterium tumefaciens (density) in the infection mediumgreatly influences the survival frequency of cultures at each step of the in vitro process. Selection and regeneration frequency of E.callus of maize varies with bacterial 
Table 1 Effect of Agrobacterium co-cultivation of callus at different ages after its initiation on survival frequency at different stages of in vitro culture in two maize genotypes

\begin{tabular}{llllll}
\hline Age of callus & Genotype & Subculture & Selection-I & Selection-II & Regeneration \\
\hline $\mathbf{0}$ days & NM74C & $42.00 \pm 7.00$ & $4.66 \pm 1.52$ & $1.00 \pm 1.00$ & $0.00 \pm 0.00$ \\
& NM5884 & $52.66 \pm 3.51$ & $15.66 \pm 2.08$ & $9.66 \pm 2.08$ & $4.33 \pm 0.57$ \\
$\mathbf{1 0}$ days & NM74C & $48.5 \pm 5.77$ & $9.28 \pm 4.04$ & $1.42 \pm 0.57$ & $0.00 \pm 0.00$ \\
& NM5884 & $67.00 \pm 4.93$ & $33.00 \pm 5.29$ & $16.75 \pm 2.51$ & $7.50 \pm 1.73$ \\
$\mathbf{2 0}$ days & NM74C & $66.0 \pm 6.35$ & $30.17 \pm 2.88$ & $4.31 \pm 2.88$ & $1.20 \pm 0.50$ \\
& NM5884 & $82.63 \pm 2.08$ & $67.63 \pm 3.04$ & $45.69 \pm 8.02$ & $25.13 \pm 6.80$ \\
$\mathbf{3 0}$ days & NM74C & $54.33 \pm 6.50$ & $12.66 \pm 2.30$ & $2.50 \pm 1.00$ & $1.06 \pm 0.00$ \\
& NM5884 & $81.00 \pm 5.29$ & $57.17 \pm 6.02$ & $38.66 \pm 4.72$ & $18.83 \pm 1.52$ \\
$\mathbf{4 0}$ days & NM74C & $46.8 \pm 5.85$ & $9.83 \pm 2.08$ & $2.16 \pm 0.57$ & $0.00 \pm 0.00$ \\
& NM5884 & $75.33 \pm 7.37$ & $43.33 \pm 7.63$ & $26.50 \pm 5.29$ & $9.66 \pm 1.52$ \\
\hline
\end{tabular}

culture measured at $580 \mathrm{~nm}$. At lower concentration, decreased transformation frequency was observed, and at higher concentration, overgrowth of bacterial culture was observed, and explants turned to necrotic. In the present study, the influence of three different concentrations viz., 0.6, 0.8, and $1.0 \mathrm{OD}$ at $580 \mathrm{~nm}$ during logarithmic growth stage on transformation efficiency of $\mathrm{E}$. calli were evaluated. Bacterial cells were harvested when the culture attains the optical density of 0.6, 0.8, and 1.0 and used for co-cultivation. Among these concentrations, IEs co-cultivated with the cultures having 0.8 OD resulted in maximum survival frequency of callus at subculture stage (87\%), two levels of selection stages (57 and $37 \%)$ as well as regeneration stage (23\%) (Table 2). On the other hand, 0.6 OD showed very low survival rate at selection (17\%) and regeneration (9\%) stages, whereas $31 \%$ and $20 \%$ of frequencies were observed in selection and regeneration frequencies respectively with 1.0 OD (Table 2).

\section{Effect of infection medium/ Agrobacterium resuspension medium}

Agrobacterium population, after reaching the density of 0.8 at $580 \mathrm{~nm}$, was centrifuged at $6000 \mathrm{rpm}$ at $4{ }^{\circ} \mathrm{C}$ for $20 \mathrm{~min}$ to get the sediment cells of bacteria. It was resuspended in infection medium, for which three types of media viz., half MS, full MS and LS media have been used. The concentration of ions present in the medium influences the rate of infection and survival of the bacterial cells. Among the three media used in this study, half MS was found to be the best one for suspending the bacteria for co-cultivation. When the full LS medium was used, the explants became brown and resulted in very low survival frequency on selection medium II (14\%) and regeneration medium (12\%); on the other hand, MS medium supports the survival rates better than the LS medium; however, the maximum frequency of survival and transformation was observed more with half MS viz., $41 \%$ and $22 \%$ respectively when compared with the full MS medium (Table 2).

\section{$\mathrm{pH}$ of the infection medium}

Hydrogen ion concentration $(\mathrm{pH})$ of the infection media used for co-cultivation is an equally important factor in transformation efficiency. $\mathrm{pH}$ of infection medium at $5.2,5.4$, and 5.8 were used in co-cultivation and the survival frequencies of callus before transferring to selection medium, on selection media I and II and frequency of regeneration were studied. Among the three $\mathrm{pH}$ used, at $\mathrm{pH} 5.2$, survival frequencies of cultures were found to be minimum at all stages (19\% on selection medium II, $14 \%$ on regeneration). A pH of 5.8 was found to be very suitable for co-cultivation and resulted in maximum survival frequencies on selection (40\%) as well as regeneration (22\%) stages (Table 2).

\section{Influence of acetosyrengone concentration}

Acetosyringone supplementation in the co-cultivation media influences the survival frequency of culture, which enhances the infection frequency during co-cultivation; in turn, it is also essential for successful transformation. In the present study, two concentrations of acetosyringone viz., 100 and $200 \mu \mathrm{M}$ were evaluated. A concentration of $100 \mu \mathrm{M}$ was found to be effective in yielding maximum survival frequencies of cultures and regeneration (39\% and $24 \%$ respectively) (Table 2 ). In the contrary, $200 \mu \mathrm{M}$ concentration resulted in comparatively lower rates of survival frequencies than $100 \mu \mathrm{M}$ acetosyringone. Infection media without acetosyringone which acts as control were also found to be less effective by showing the survival frequencies of 18 and $10 \%$ of callus on selection and regeneration media respectively (Table 2). 
Table 2 Survival frequency of in vitro cultures at three different stages and their frequency of regeneration in maize affected by different parameters with different variables involved in Agrobacterium-mediated transformation after co-cultivation

\begin{tabular}{|c|c|c|c|c|c|}
\hline Parameter & Variable & Subculture & Selection-I & Selection-II & Regeneration \\
\hline \multirow[t]{3}{*}{ Optical density of bacterial culture } & 0.6 & $60.17 \pm 5.13$ & $28.59 \pm 4.04$ & $17.19 \pm 3.51$ & $8.94 \pm 1.00$ \\
\hline & 0.8 & $86.93 \pm 4.50$ & $57.41 \pm 7.76$ & $37.09 \pm 4.72$ & $23.38 \pm 3.51$ \\
\hline & 1 & $73.55 \pm 9.50$ & $46.00 \pm 3.60$ & $30.66 \pm 5.29$ & $19.55 \pm 6.50$ \\
\hline \multirow[t]{3}{*}{ Strength of the infection medium } & Half MS (plain) & $87.93 \pm 2.00$ & $49.48 \pm 5.50$ & $40.51 \pm 3.51$ & $21.89 \pm 3.51$ \\
\hline & Full MS (plain) & $83.20 \pm 5.56$ & $36.98 \pm 8.08$ & $28.11 \pm 6.80$ & $16.60 \pm 3.78$ \\
\hline & LS inf & $74.92 \pm 6.65$ & $23.07 \pm 5.00$ & $14.46 \pm 6.11$ & $12.30 \pm 5.03$ \\
\hline \multirow[t]{3}{*}{$\mathrm{pH}$ of the infection medium } & $\mathrm{pH} 5.2$ & $50.00 \pm 8.88$ & $30.00 \pm 2.64$ & $18.88 \pm 2.64$ & $13.70 \pm 2.08$ \\
\hline & $\mathrm{pH} 5.4$ & $70.30 \pm 6.65$ & $40.61 \pm 2.64$ & $29.69 \pm 5.03$ & $18.61 \pm 2.08$ \\
\hline & $\mathrm{pH} 5.8$ & $82.57 \pm 5.77$ & $60.60 \pm 8.50$ & $39.84 \pm 3.78$ & $21.51 \pm 5.03$ \\
\hline \multirow[t]{3}{*}{ Acetosyrengone concentration } & $0 \mu \mathrm{M}$ & $50.28 \pm 4.16$ & $33.71 \pm 1.15$ & $17.71 \pm 3.05$ & $9.71 \pm 1.15$ \\
\hline & $100 \mu \mathrm{M}$ & $84.21 \pm 5.68$ & $63.28 \pm 7.00$ & $38.59 \pm 2.51$ & $23.59 \pm 2.08$ \\
\hline & $200 \mu \mathrm{M}$ & $73.40 \pm 2.51$ & $56.13 \pm 6.42$ & $28.40 \pm 5.50$ & $18.86 \pm 4.50$ \\
\hline \multirow[t]{3}{*}{ Macerozyme treatment } & $0.1 \%$ & $57.16 \pm 5.13$ & $36.16 \pm 3.78$ & $21.33 \pm 5.03$ & $12.50 \pm 3.00$ \\
\hline & $0.2 \%$ & $42.83 \pm 4.04$ & $20.50 \pm 6.55$ & $17.00 \pm 3.46$ & $10.66 \pm 2.51$ \\
\hline & $0.5 \%$ & $28.83 \pm 7.50$ & $12.33 \pm 6.42$ & $10.16 \pm 5.13$ & $6.33 \pm 5.03$ \\
\hline \multirow[t]{3}{*}{ Vacuum infiltration } & $0 \mathrm{~min}$ & $83.33 \pm 7.63$ & $46.16 \pm 4.17$ & $34.16 \pm 3.51$ & $17.00 \pm 2.00$ \\
\hline & $10 \mathrm{~min}$ & $61.42 \pm 9.07$ & $33.28 \pm 3.78$ & $22.71 \pm 4.58$ & $11.28 \pm 1.52$ \\
\hline & $15 \min$ & $58.62 \pm 5.77$ & $28.79 \pm 2.08$ & $16.72 \pm 2.51$ & $7.93 \pm 1.15$ \\
\hline \multirow[t]{3}{*}{ Infection time } & $10 \mathrm{~min}$ & $80.32 \pm 7.63$ & $54.91 \pm 7.63$ & $38.68 \pm 5.50$ & $22.78 \pm 5.13$ \\
\hline & $15 \min$ & $70.66 \pm 5.29$ & $44.22 \pm 3.21$ & $22.44 \pm 5.13$ & $17.11 \pm 0.57$ \\
\hline & $30 \mathrm{~min}$ & $58.97 \pm 5.00$ & $33.33 \pm 3.00$ & $12.99 \pm 5.03$ & $6.32 \pm 0.57$ \\
\hline \multirow[t]{3}{*}{ Co-cultivation period } & 2 days & $84.00 \pm 3.60$ & $52.00 \pm 9.16$ & $36.66 \pm 1.15$ & $27.66 \pm 1.52$ \\
\hline & 3 days & $66.33 \pm 9.01$ & $36.66 \pm 8.50$ & $23.00 \pm 3.46$ & $15.83 \pm 2.51$ \\
\hline & 4 days & $30.65 \pm 5.00$ & $13.69 \pm 1.73$ & $15.00 \pm 2.00$ & $7.17 \pm 1.00$ \\
\hline
\end{tabular}

\section{Effect of pretreatment with macerozyme solution}

Macerozyme treatment helps the bacteria to penetrate into the cells by digesting the cell wall of the explant so that the penetration of the T-DNA and the vir-genes becomes easy which results in the high frequencies of transformation. Pretreatment with macerozyme was performed with different concentrations viz., $0.1,0.2$, and $0.5 \%$ for $5 \mathrm{~min}$ before infecting with bacteria. Macerozyme effect was negatively correlated with the survival frequencies of cultures at all stages i.e., survival frequency of callus on selection and regeneration media were found to be decreased with increasing treatment concentration of macerozyme (Table 2). Among the three concentrations used, $0.1 \%$ was found to be the best, resulting in $21 \%$ and $13 \%$ of survival frequencies on selection and regeneration media respectively. Explants treated with macerozyme showed necrosis after a few weeks and failed to develop further in all concentrations; hence, the treatment has not been considered further.
Influence of vacuum infiltration for the explants

Vacuum infiltration is another way to enhance the frequency of transformation. Hence, in the present study, time duration of vaccum pressure was standardized. A radical decrease in the efficiency of transformation was observed compared with control in which no vacuum infiltration was applied (Table 2). The survival frequency was higher where no vacuum treatment was applied. Survival frequencies (34\% and 17\%) were found in the selection and regeneration stages respectively. In the contrary, the 10-min vacuum infiltration has given a $23 \%$ selection frequency and $11 \%$ regeneration frequency. However, the least frequency was observed in the 15 -min time duration of $17 \%$ and $8 \%$ (Table 2).

\section{Effect of infection time}

The effect of infection time on transformation frequency has been studied by using different time periods viz., 10 , 15 , and $30 \mathrm{~min}$, of which the 10-min time duration has given a maximum selection (39\%) and regeneration (23\%) frequencies; as time duration increases, the 
frequency was decreased. Prolonged infection time adversely affected the explant because of bacterial overgrowth. The minimum frequency was observed in 30 min time duration for selection (13\%) and regeneration (6\%) (Table 2).

\section{Influence of co-cultivation period}

After infecting the cultures with Agrobacterium, they were transferred onto the medium supplemented with acetosyrengone at a concentration of $100 \mu \mathrm{M}$ and incubated in dark for different time periods viz., 2, 3, and 4 days. Survival frequency was found to be maximum in those cultures which were incubated for 2 days and resulted in $37 \%$ and also maximum regeneration frequency of $28 \%$. On the other hand, both survival as well as regeneration frequencies were found to be decreased with the increase in incubation period (Table 2).

Immature embryos of NM5884 inbred line were inoculated in larger numbers by adopting the conditions which were found to be suitable and yielded higher frequencies of the survival of cultures and regeneration to evaluate the frequency of transformation which was found to be $6 \%$ (Table 3). Putative plants that survived on the selection media were subjected to molecular characterization through testing with PCR by using marker (hygromycin)-specific primers and gene-specific markers viz., rpk and nced. Putative transgenics which were found to be positive in PCR and show good agronomical characters with good seed set have been considered as elite transgenic lines. Three such lines were selected, and seeds were collected from these elite transgenic lines $\left(\mathrm{T}_{0}\right)$ viz., ET-2, ET-5 and ET-9, which were forwarded to $T_{1}$ generation. Twenty plants raised from each of these three lines (i.e., ET-2-1 to 20, ET-5-1 to 20, and ET-9-1 to 20) were used for screening with PCR. Fifteen plants, five plants from each of the three lines, which were positive in PCR screening, have been used for physiological and biochemical characterization. Out of these 15 plants, nine plants, three plants from each of the three lines after physiological and biochemical analyses have been subjected to southern analysis using the probe designed for nced gene by adopting nonradioactive labeling method, to assess the number of inserts in the transgenic maize plants. The resulted transgenic plants were found to have 1-2 copies of genes (Fig. 3).

\section{Physiological and biochemical characterization (in vitro)}

Prior to the experiments for biochemical and physiological characterization, effective concentration of methyl viologen and treatment time have been established by simulating the stress by using different concentrations viz., 50, 100, 150, 200, 250,300, 350, 400, 450, and 500 $\mu \mathrm{M}$, for $12-, 24-$, and $36-\mathrm{h}$ intervals using the non transgenic plants (control). At the end of the treatment, effective concentration and time were evaluated by considering the degree of damage caused in the pigment quantities under the stress. The $250-\mu \mathrm{M}$ methyl viologen treatment for $36 \mathrm{~h}$ was found to be effective for screening the transgenics. The same treatment concentration and time have been used for all experiments designed for physiological and biochemical characterization, for which ion leakage, lipid peroxidation, proline accumulation and analyses of photosynthetic pigments viz., chlorophyll-A, chlorophyll-B, total chlorophyll, and total carotenoids were studies in three elite lines viz., ET-2, ET-5, and ET-9, represented as Trg-1, 2, and 3 respectively. In each line, five plants were analyzed. For all these experiments, non transgenic maize plants were served as control plants. All the physiological and biochemical studies were studies in transgenic and control plants under both stressed and unstressed conditions. In all the experiments done in vitro, elevated levels of biochemical activity in transgenics over the control plants that were not exposed to methyl viologen were shown, to mitigate the stress for surviving. Since most of the symptoms have been related to membrane damage, experiments have been conducted as a function of electrical conductivity (EC) in the medium where the stressed and unstressed leaf discs of transgenics and control plants have been grown. Significant increase in ion leakage as a function of electrical conductivity has been observed between stressed and unstressed controls; on the other hand, no significant differences have been observed between any of the transgenics (Fig. 4). Membrane damage has also been studied biochemically through lipid peroxidation by measuring the MDA (malondialdehyde) levels in stressed and unstressed controls and transgenics plants (Fig. 5). MDA content in control was found to be increased in stressed condition, whereas in transgenics, MDA-reactive substances were observed to be decreased under stress (Fig. 5). Proline accumulation studies revealed that though both control as well as transgenic plants accumulated more proline under stress than their

Table 3 Transformation frequency obtained on hygromycin regime and molecular screening of putative transgenics through PCR using hpt /l primers of maize obtained through Agrobacterium-mediated transformation

\begin{tabular}{lllllll}
\hline $\begin{array}{l}\text { No. of immature } \\
\text { embryos co-cultivated }\end{array}$ & $\begin{array}{l}\text { Survival frequency at } \\
\text { subculture stage }\end{array}$ & $\begin{array}{l}\text { Survival frequency } \\
\text { in Selection-I }\end{array}$ & $\begin{array}{l}\text { Survival frequency } \\
\text { in Selection-II }\end{array}$ & $\begin{array}{l}\text { Regeneration } \\
\text { frequency }\end{array}$ & $\begin{array}{l}\text { PCR +ves } \\
\text { for hpt II }\end{array}$ & $\begin{array}{l}\text { Transformation } \\
\text { frequency (\%) }\end{array}$ \\
\hline 5697 & $86.29(4916)$ & $71.19(4056)$ & $46.58(2654)$ & $29.1(1658)$ & 329 & 5.77 \\
\hline
\end{tabular}

Numbers in parenthesis indicate total number of calli tested 


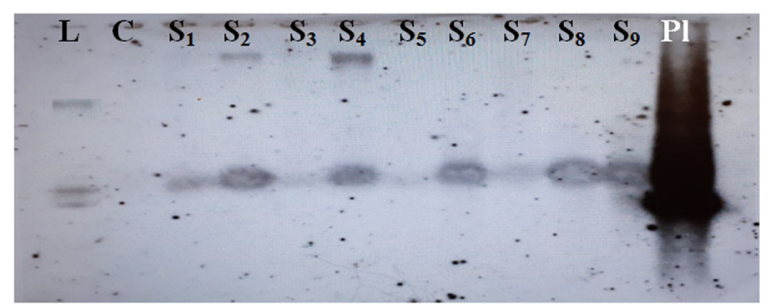

Fig. 3 Molecular characterization of putative transgenic maize plants regenerated after Agrobacterium-mediated transformation through southern blot analysis carried out using gene (nced)-specific probe through non-radioactive labeling method. C control, PI plasmid, $L$ ladder, S1-S9 samples 1-9

corresponding counter plants under normal (unstress) conditions, accumulation of proline in transgenic plants was significantly more than in control plants. Among the transgenics, Trg-2 (ET-5) accumulated more proline (Fig. 5). Analysis of photosynthetic pigments viz., chlorophyll-A, chlorophyll-B, and total chlorophylls and carotenoids revealed that except carotenoids, chlorophyll-A, chlorophyll-B, and total chlorophyll were found to be decreased or remain unchanged under stress condition in transgenics when compared with normal (unstress) condition, whereas in control plants, decrease in pigment content were more in stress conditions. On the other hand, carotenoid content was found to be unchanged or slightly increased in all transgenics; whereas in nontransgenics, pigment content was found to be unchanged or slightly decreased (Fig. 5).

\section{Pot experiment of transgenic maize for drought screening (in vivo)}

In order to screen the transgenics in poly house, pot experiments were conducted with three independent

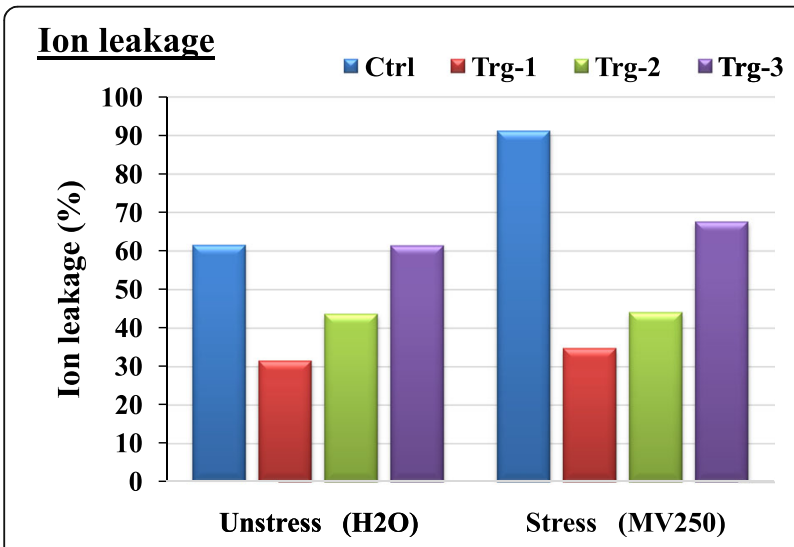

Fig. 4 Physiological characterization of putative transgenic maize plants (Trg1-3) regenerated after Agrobacterium-mediated transformation and their corresponding untransformed control plants through ion leakage by studying electrical conductivity under normal condition (unstressed) and after giving simulated stress with methyl viologen transgenic plants (ET-2-3, ET-5-17, and ET-9-14) along with wild-type control under severe water deficit condition (9 days). After 9 days, plants were recovered by pouring the water equally to all plants. Leaf samples were collected and subjected to enzyme assay for ABA. ABA content was measured using the HPLC method, for which standards have been run, retention time (RT) identified (Fig. 6A), and the standard curve prepared. Then the samples, controls, and transgenics were analyzed by comparing with the standard chromatograms (Fig. 6A, B), and results have been presented in Fig. 7 . ABA content was found to be increased in all transgenics under stress condition when compared with their corresponding counters in the unstress condition, whereas the control plants showed decreased ABA content under stress condition (Fig. 7). Among the transgenic plants, Trg-2 (ET-5) showed more accumulation of ABA than the other two events viz., Trg1 and Trg3 (ET-2 and ET-9). The transgenic plants exposed to drought in pot experiments (in vivo) showed significant survival capacity over the control plants. They were left for 14 days, where the control plants under stress (without water) were completely dried and transgenics were left green (Fig. 8). Among the transgenic plants, Trg-2 (ET-5) was found to be more tolerant than the other two based on in vitro (physiological and biochemical) and in vivo (pot experiment) screenings.

\section{Discussion}

Genes involved in the biochemical pathways which control the reactive oxygen species in the abiotic stress conditions have been introduced and over expressed in the crop plants to develop the stability even in the drastic multiple stress conditions viz., drought, water logging, and very high and low temperatures. Many of such abiotic stress-related genes have been isolated and characterized in many of the crop plants $[29,30]$. The regulatory components of the drought response have also been identified [31, 32]. Transgenics in different crop plants were developed through up-regulating the general stress response and also the specific physiological pathways which were found to be involved in the stress management processes [33, 34]. Most of the genes involved in drought stress tolerance will be influenced by the ABA pathway, and hence, the genes within the ABA pathway or other genes that alters that pathway will influence the drought tolerance [35]. In the present study, two genes nced and rpk genes which involved in the ABA pathway have been introduced into maize. Sreenu et al. [36] introduced five genes viz., sod, apx, gr, dhar, and mdhar, which play key roles in the ascorbateglutathione pathway by using Agrobacterium-mediated transformation in maize to develop drought-tolerant plants. Li et al. [37] developed tomato transgenics with 


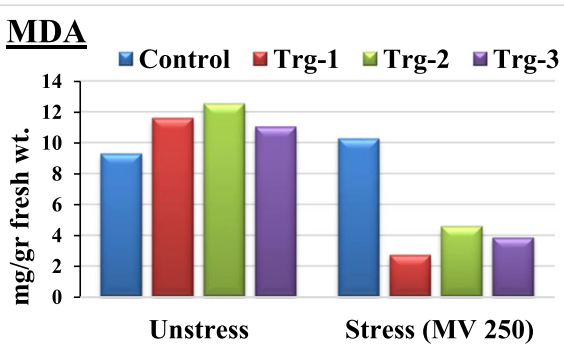

\section{Chlorophyll-A}

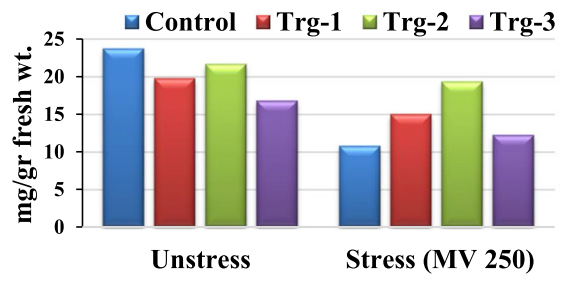

Total chlorophyll

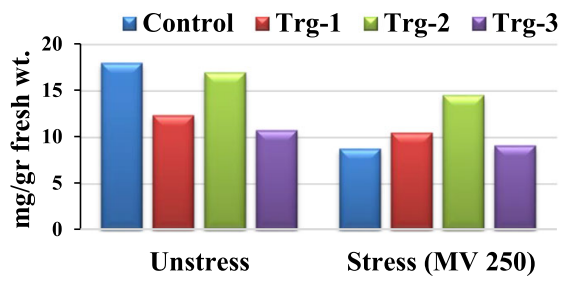

\section{Proline}

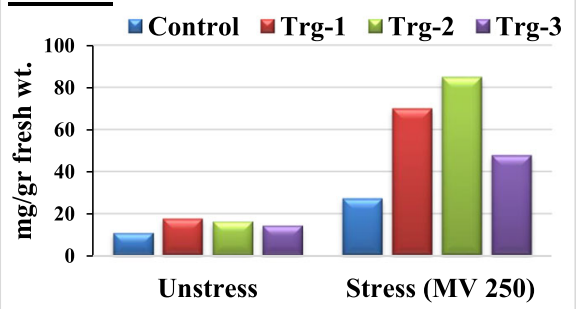

\section{Chlorophyll-B}

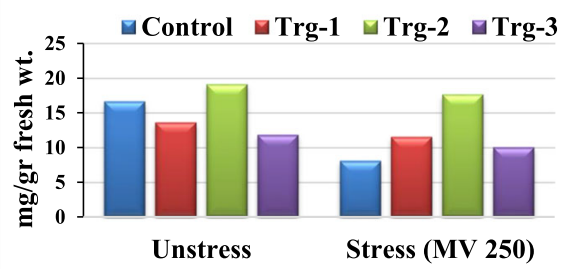

$\underline{\text { Total carotenoids }}$

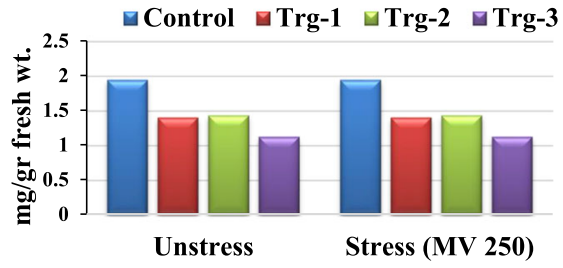

Fig. 5 Physiological and biochemical characterization of putative transgenic maize plants (Trg1-3) regenerated after Agrobacterium-mediated transformation and their corresponding untransformed control plants through lipid peroxidation, proline estimation, pigment analyses by studying chlorophyll-A, chlorophyll-B, and total chlorophyll and total carotenoids under normal condition (unstressed) and after giving simulated stress with methyl viologen

dhar1 and dhar2 genes, where dhar1 showed increased ascorbate content and DHAR activity in both the leaves and fruits. Likewise, in tobacco, transgenic plants were developed with antioxidative enzymes coding genes singly and in combination viz., dhar or gst, or combination of dhar:gr and gst:gr [38]. Eltelib et al. [39] reported higher amount of ascorbate (AsA) in transgenic tobacco plants generated by mdhar gene isolated from Malpighia glabra L. During pot experiment (dehydration stress), non transgenic control plants showed wilting and complete drying after exposing to stress for long time, whereas transgenic lines survived without any wilting. Performance of transgenic plants (ET-2, ET-5, and ET9) was relatively commendable in terms of several growth as well as biochemical and physiological parameters in comparison with their respective non-transgenic control lines during simulated drought stress condition. By considering in vitro as well as in vivo studies together, the over expression of the two genes viz., nced and $r p k$ resulted in good stability in stress and increased the tolerance positively.
As maize is an important crop with a wide range of utilization as food and fodder, extensive exploration of suitable conditions and materials for the development of the crop has been done. For in vitro studies and transformation, almost all the plant parts have been used viz., immature tassels [40], shoot tips [41, 42], germinated split seeds [43], mature embryos [44], and coleoptile nodes $[36,45]$. Among all the explants of maize used, immature embryos were found to be the best explants in most of the studies [46, 47]. In IEs, age and stage were crucial points in yielding high frequencies of E.callus and regeneration and hence different studies reported the optimal conditions and stage of IEs in different genotypes [48, 49].

Infecting the explants with Agrobacterium is an initial step in transformation; Sreenu et al. [36] reported that infecting the explants (coleoptilar node) with Agrobacterium was a suitable method rather than infecting the E.callus in NM81A maize inbred line, where the antagonistic effect was noticed when infection was given to callus. In case of immature embryos, the E. calli 

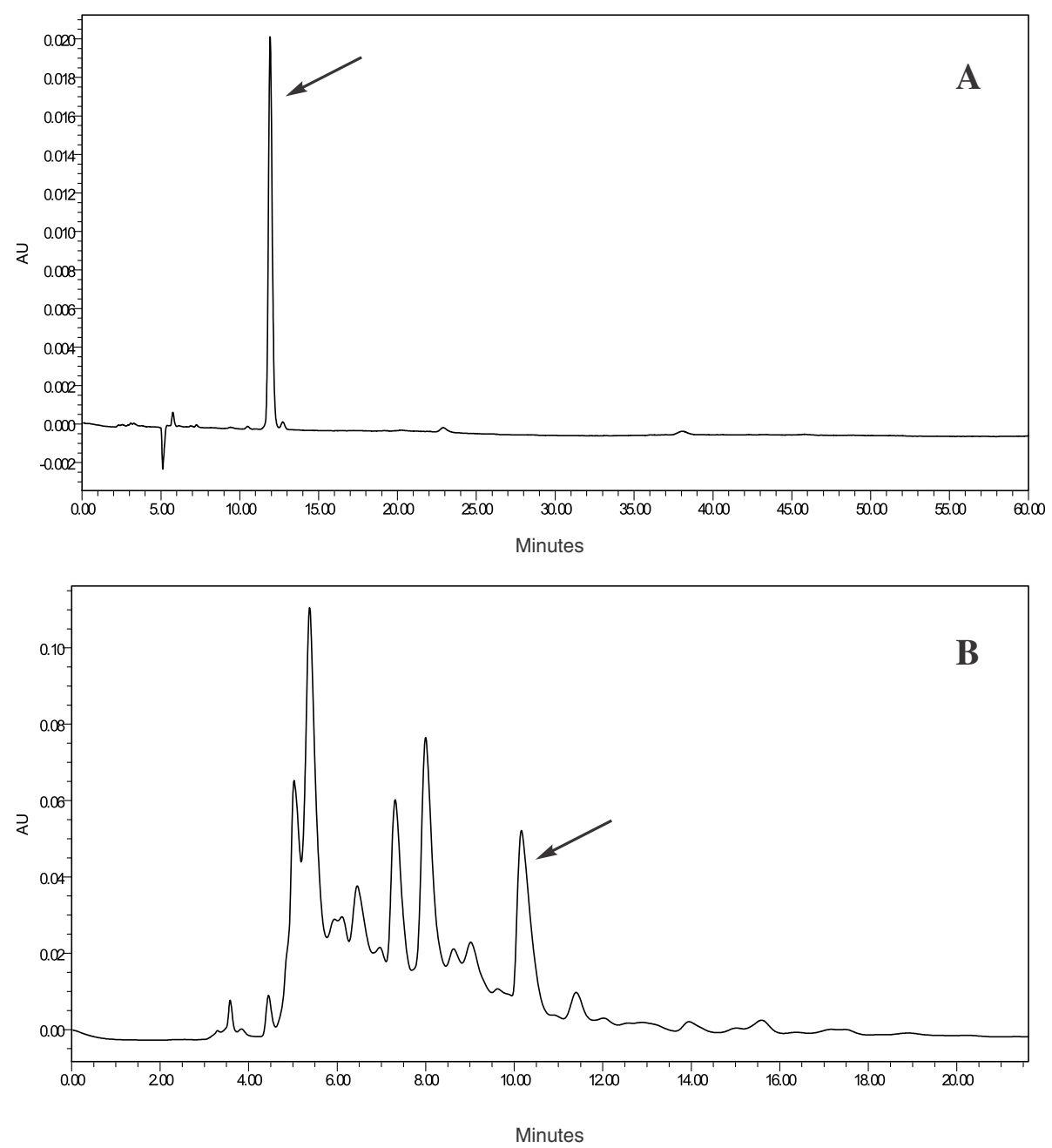

Fig. 6 Chromatograms of standard solution of $A B A(\mathbf{A})$ and extract of maize plant $(\mathbf{B})$ where the arrows represent the ABA peak in both pictures with retention time of $\sim 11 \mathrm{~min}$

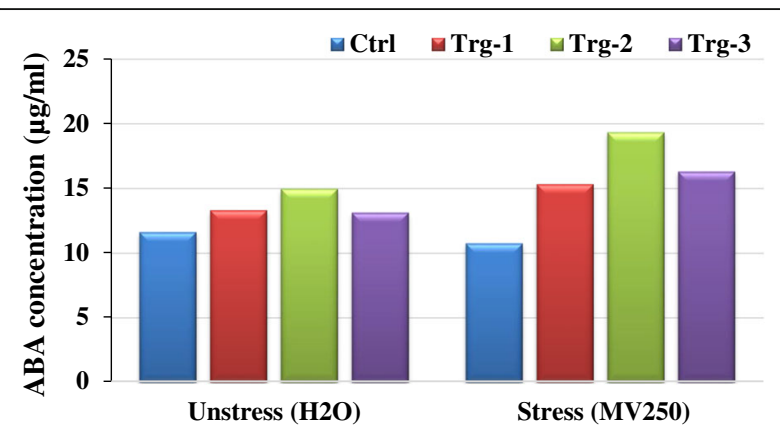

Fig. 7 Biochemical characterization of putative transgenic maize plants (Trg1-3) regenerated after Agrobacterium-mediated transformation and their corresponding untransformed control plants through ABA enzyme assay under normal condition (unstressed) and after giving simulated stress with methyl viologen especially type II was infected with Agrobacterium and reported a high frequency of genetic transformation [50]; on the other hand, Ombori et al. [51] gave infection to the IE's (explants). In the present study, infection has been given to the explants (IEs) which resulted in the browning of explants and finally death without further growth. Hence, the explants were subjected to infection after callus initiation at different time periods. This discrepancy indicated that the genotype plays the role in withstanding for infection to results in high frequencies of transformation. In maize inbred line NM5884, which was used in the present study, Sreenu et al. [52] reported the transient expression of GUS, where the E. calli were subjected to microprojectile bombardment, where no infection/co-cultivation step is involved, rather than explant. Such discrepancies have also been noticed in the reports of Saker et al. [53] in rice and Tadesse et al. [54] in sorghum, where the calli 


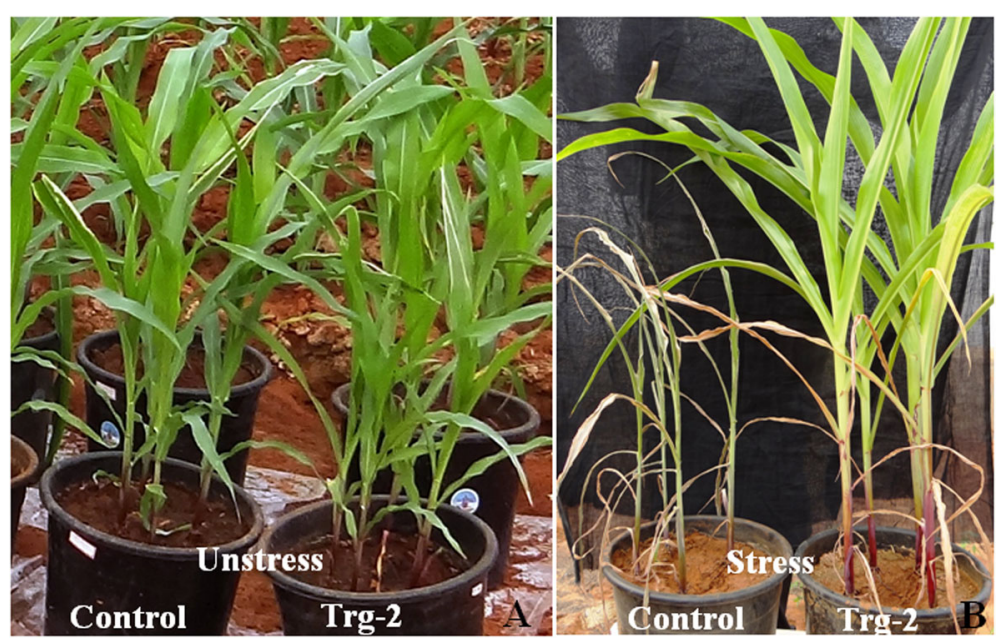

Fig. 8 Wild-type and transgenic lines (Trg-2) under well water (A) and 14 days of water withholding condition (B), tolerant green transgenic (right in B), and completely dried non-transgenic (left in B) maize plants under drought stress given in pot experiment at the end of 14 days

and explants were bombarded respectively. Hence, while doing the transformation, not only genotype and explants but also the method used to introduce the TDNA has to be considered to achieve the high frequencies of transformation, because in the same genotype (NM5884), when the explants were infected with Agrobacterium, no further growth was observed and became necrotic; on the other hand, infection given to IEs after 20 days inoculation resulted in a high frequency of transformation. In the contrary, vice versa results were observed with microprojectile bombardment [52].

Media and its components play important role for in vitro growth and regeneration, mostly MS media was used for different explants. Abbas et al. [55], Sreenu et al. [36], and Pavan Kumar et al. [45] established the in vitro cultures and Agrobacterium-mediated transformation protocols by using MS medium with coleoptilar nodal explants in maize. In the present study, the LS medium has been used and found to be more suitable for the immature embryos, which has also been reported in earlier studies $[16,19]$.

Genotype is also critical and associated with the explant for in vitro growth and regeneration. Sridevi et al. [19] reported that inbred line NM5884 is suitable for using IEs as explants, whereas another inbred line NM74C has been reported suitable for using coleoptilar node as an explant [45]. In the present study, it has been further confirmed that NM5884 is the most suitable genotype for using IEs not only for in vitro studies but also for genetic transformation in maize.

In the process of Agrobacterium-mediated transformation, every step is crucial and specific for genotype and explants used; hence, by varying every parameter, growth and regeneration efficiency was studied at pre-selection and selection stages as well as at the regeneration stage. Pre-culturing of explants before infection is necessary for some genotypes, where the explants did not respond without pre-culturing. Sreenu et al. [36] reported $24 \mathrm{~h}$ of pre-culturing of explant resulted in best results than the other explants given by no pretreatment and longer (48 h.) pretreatments. Wu et al. [56] and Takavar et al. [57] reported similar results in wheat and maize respectively. In the present study, culturing of the explants for a longer period (20 days) has a positive response after induction of the callus. Other parameters that involve and influence the transformation frequency were optimized by several workers by using different explants in different genotypes. Present results have similarities as well as differences with their reports which again confirmed that the conditions are dependent on the genotype, explants, and method of transformation used [36, 49].

\section{Conclusions}

In maize, development of transgenic plants through in vitro pyramiding of different genes involved in the biochemical pathways that regulates different physiological activities in regulating the multiple stresses in plants is very essential. In this sequence, optimization of conditions and various parameters of transformation improve the transformation frequency. In the present study, introducing two genes involved in the ABA pathway, using gateway technology is useful for developing stable transgenic plants with desired characters (i.e., abiotic stress tolerance). This study also provided the optimized conditions and parameters of Agrobacteriummediated transformation to yield maximum frequency of transformation within NM5884 inbred line. 


\section{Abbreviations}

2, 4-D: 2, 4-Dichlorophenoxy acetic acid; ABA: Abscisic acid; ANOVA: Analysis of variance; BAP: 6-Benzylaminopurine; C-TAB: Cetyltrimethylammonium bromide; DAP: Days after pollination; DNA: Deoxyribonucleic acid; E.callus: Embryogenic callus; hpt Il: Hygromycin phosphotransferase gene; IEs: Immature embryos; LB: Luria Bertani broth; nced: Nine-cisepoxycarotenoid dioxygenase; rpk: Receptor-like protein kinases; TDNA: Transfer DNA

\section{Acknowledgements}

This work was financially supported by IGSTC (Indo-German Science and Technology Centre, New Delhi, India), a binational centre supported by the government of India and the government of Germany. Project was sanctioned under IGSTC (2 + 2 scheme) (IGSTC/First Call/ICGEB-001/2011/ 157). The authors are thankful for the support.

\section{Authors' contributions}

GPK designed the work, carried out the southern analysis, analyzed the data, and wrote the manuscript. MS conducted the experiments. MKR developed the construct and provided with Agrobacterium tumefaciens strain EHA105. DP designed and assisted in physiological and biochemical characterization experiments. PSK has reviewed the final manuscript. The authors have read and approved the final manuscript.

\section{Funding}

This work was financially supported by IGSTC (Indo-German Science and Technology Centre, New Delhi, India), a binational centre supported by the government of India and the government of Germany. Project was sanctioned under IGSTC (2 + 2 scheme) (IGSTC/First Call/ICGEB-001/2011/ 157). The funds have been utilized for purchasing instruments, chemicals, and other consumables required for the project.

\section{Availability of data and materials}

Not applicable.

\section{Declarations}

Ethics approval and consent to participate

Not applicable.

\section{Consent for publication}

Not applicable.

\section{Competing interests}

The authors declare that they have no competing interests.

\section{Author details}

'Department of Biotechnology, Nuziveedu Seeds Limited, Hyderabad, Telangana 501401, India. '2Department of Biotechnology, Jawaharlal Nehru Technological University, Hyderabad, Telangana 500085, India. ${ }^{3}$ Department of Plant Molecular Biology, International Centre for Genetic Engineering and Biotechnology, New Delhi 110067, India.

\section{Received: 12 January 2021 Accepted: 9 June 2021}

Published online: 24 June 2021

\section{References}

1. Nambara E, Marion-Poll A (2005) Abscisic acid biosynthesis and catabolism. Ann Rev Plant Biol 56(1):165-185. https://doi.org/10.1146/annurev.arplant.56. 032604.144046

2. Nilson SE, Assmann SM (2007) The control of transpiration: insights from Arabidopsis. Plant Physiol 143(1):19-27. https://doi.org/10.1104/pp.1 06.093161

3. Tan BC, Schwartz SH, Zeevaart JA, McCarty DR (1997) Genetic control of abscisic acid biosynthesis in maize. Proc Natl Acad Sci 94(22):12235-12240. https://doi.org/10.1073/pnas.94.22.12235

4. Schwartz SH, Qin X, Zeevaart JA (2003) Elucidation of the indirect pathway of abscisic acid biosynthesis by mutants, genes, and enzymes. Plant Physiol 131(4):1591-1601. https://doi.org/10.1104/pp.102.017921

5. Thompson AJ, Jackson AC, Symonds RC, Mulholland BJ, Dadswell AR, Blake PS, Burbidge A, Taylor IB (2000) Ectopic expression of a tomato 9-cis- epoxycarotenoid dioxygenase gene causes over-production of abscisic acid. Plant J 23(3):363-374. https://doi.org/10.1046/j.1365-313x.2000.00789.x

6. Iuchi S, Kobayashi M, Taji T, Naramoto M, Seki M, Kato T, Tabata S, Kakubari Y, Yamaguchi-Shinozaki K, Shinozaki K (2001) Regulation of drought tolerance by gene manipulation of 9-cis-epoxycarotenoid dioxygenase, a key enzyme in abscisic acid biosynthesis in Arabidopsis. Plant J 27(4):325333. https://doi.org/10.1046/j.1365-313x.2001.01096.x

7. Pedrosa AM, Cidade LC, Martins CPS, Macedo AF, Neves DM, Gomes FP, Floh EIS, Costa MGC (2017) Effect of over expression of citrus 9-cisepoxycarotenoid dioxygenase 3 (CSNCED3) on the physiological response to drought stress in transgenic tobacco. Genet Mol Res 16:gmr16019292. https://doi.org/10.4238/gmr16019292

8. Wan XR, Li L (2006) Regulation of ABA level and water-stress tolerance of Arabidopsis by ectopic expression of a peanut 9-cis-epoxycarotenoid dioxygenase gene. Biochem Biophys Res Commun 347(4):1030-1038. https://doi.org/10.1016/j.bbrc.2006.07.026

9. Sultana S, Tureekova V, Ho CL, Napis S, Namasivayam P (2014) Molecular cloning of a putative Acanthus ebracteatus-9-cis-epoxycarotenoid deoxygenase (AeNCED) and its overexpression in rice. J Crop Sci Biotechnol 17(4):239-246. https://doi.org/10.1007/s12892-014-0006-4

10. Estrada-Melo AC, Ma C, Reid MS, Jiang CZ (2015) Overexpression of an ABA biosynthesis gene using a stress-inducible promoter enhances drought resistance in petunia. Hortic Res 2(1):15013. https://doi.org/10.1038/hortres.2 015.13

11. de Souza AMS, Batista VGL, Pinheiro MPN, Suassuna JF, de Lima LM, Fernandes PD (2016) Expression of NCED gene in colored cotton genotypes subjected to water stress. Rev Bras Eng Agríc Ambient 20(8):692-696. https://doi.org/10.1590/1807-1929/agriambi.v20n8p692-696

12. Tong SM, Xi HX, Ai KJ, Hou HS (2017) Overexpression of wheat TaNCED gene in Arabidopsis enhances tolerance to drought stress and delays seed germination. Biol Plantarum 61(1):64-72. https://doi.org/10.1007/s10535-0160692-5

13. Bartels D, Sunkar R (2005) Drought and salt tolerance in plants. Crit Rev Plant Sci 24(1):23-58. https://doi.org/10.1080/07352680590910410

14. Yamaguchi-Shinozaki K, Shinozaki K (2006) Transcriptional regulatory networks in cellular responses and tolerance to dehydration and cold stresses. Ann Rev Plant Biol 57(1):781-803. https://doi.org/10.1146/annurev.a rplant.57.032905.105444

15. Osakabe Y, Mizuno S, Tanaka H, Maruyama K, Osakabe K, Todaka D, Fujita Y, Kobayashi M, Shinozaki K, Yamaguchi-Shinozaki K (2010) Overproduction of the membrane-bound receptor-like protein kinase 1, RPK1, enhances abiotic stress tolerance in Arabidopsis. J Biol Chem 285(12):9190-9201. https://doi. org/10.1074/jbc.m109.051938

16. Ishida $Y$, Hiei $Y$, Komari T (2007) Agrobacterium-mediated transformation of maize. Nat Protoc 2(7):1614-1621. https://doi.org/10.1038/nprot.2007.241

17. Du DX, Geng C, Zhang X, Zhang Z, Zheng Y, Zhang F, Lin Y, Qiu F (2014) Transgenic maize lines expressing a $c r y 1 C^{*}$ gene are resistant to insect pests. Plant Mol Biol Rep 32(2):549-557. https://doi.org/10.1007/s11105-013-0663-3

18. Hiei $Y$, Ishida $Y$, Kasaoka K, Komari T (2006) Improved frequency of transformation in rice and maize by treatment of immature embryos with centrifugation and heat prior to infection with Agrobacterium tumefaciens. Plant Cell Tiss Org Cult 87(3):233-243. https://doi.org/10.1007/s11240-006-9157-4

19. Sridevi M, Pavan Kumar G, Sreenu P, Kodandarami Reddy M, Sateesh Kumar P, Premalatha D (2020) Distinctive response of maize (Zea mays L.) genotypes in vitro with the acceleration of phytohormones. J Plant Biotechnol 47(1):26-39. https://doi.org/10.5010/JPB.2020.47.1.026

20. Doyle JJ, Doyle JL (1990) Isolation of plant DNA from fresh tissue. Focus 12 : $13-15$

21. Sambrook J, Russell DW (2001) Molecular cloning: a laboratory manual. Cold Spring Harbor Laboratory Press, Cold Spring Harbor

22. Kumari S, Joshi R, Singh K, Roy S, Tripathi AK, Singh P, Singla-Pareek SL, Pareek A (2015) Expression of a cyclophilin OsCyp2-P isolated from a salttolerant landrace of rice in tobacco alleviates stress via ion homeostasis and limiting ROS accumulation. Funct Integr Genomics 15(4):395-412. https:// doi.org/10.1007/s10142-014-0429-5

23. Heath RL, Packer L (1968) Photoperoxidation in isolated chloroplasts: . kinetics and stoichiometry of fatty acid peroxidation. Arch Biochem Biophys 125(1):189-198. https://doi.org/10.1016/0003-9861(68)90654-1

24. Bates LS, Waldren RP, Teare ID (1973) Rapid determination of free proline for water-stress studies. Plant Soil 39(1):205-207. https://doi.org/10.1007/ BF00018060 
25. Arnon DI (1949) Copper enzymes in isolated chloroplasts. Polyphenoloxidase in Beta vulgaris. Plant Physiol 24:1-15 http://www.pla ntphysiol.org/content/24/1/1

26. Dobrev PI, Vankova R (2012) Quantification of abscisic acid, cytokinin, and auxin content in salt-stressed plant tissues. In: Shabala S, Cuin T (eds) Plant salt tolerance. Methods Mol Biol, vol 913. Humana Press, Totowa, pp 251261. https://doi.org/10.1007/978-1-61779-986-0_17

27. Snedecor GW, Cochran WG (1968) Statistical methods. The lowa State University Press, Ames and Oxford and IBH publishing Co Pvt Ltd, New Delhi https://www.worldcat.org/title/statistical-methods/oclc/166320

28. Linsmaier E, Skoog F (1965) Organic growth factor requirements of tobacco tissue culture. Physiol Plant 18(1):100-127. https://doi.org/10.1111/j.1399-3 054.1965.tb06874.x

29. Cattivelli L, Baldi P, Crosatti C, Di Fonzo N, Faccioli P, Grossi M, Mastrangelo AM, Pecchioni N, Stanca AM (2002) Chromosome regions and stress-related sequences involved in resistance to abiotic stress in Triticeae. Plant Mol Biol 48(5/6):649-665. https://doi.org/10.1023/A:1014824404623

30. Ramanjulu S, Bartels D (2002) Drought and desiccation-induced modulation of gene expression in plants. Plant Cell Environ 25(2):141-151. https://doi. org/10.1046/j.0016-8025.2001.00764.x

31. Li XP, Tain AG, Luo GZ, Gong ZZ, Zhang JS, Chen SY (2005) Soybean DREbinding transcription factors that are responsive to abiotic stresses. Theor Appl Genet 110(8):1355-1362. https://doi.org/10.1007/s00122-004-1867-6

32. Mare C, Mazzucotelli E, Crosatti C, Francia E, Stanca AM, Cattivelli L (2004) Hv-WRKY38: a new transcription factor involved in cold-and droughtresponse in barley. Plant Mol Biol 55(3):399-416. https://doi.org/10.1007/ s11103-004-0906-7

33. Oh SJ, Song SI, Kim YS, Jang HJ, Kim SY, Kim M, Kim YK, Nahm BH, Kim JK (2005) Arabidopsis CBF3/DREB1A and ABF3 in transgenic rice increased tolerance to abiotic stress without stunting growth. Plant Physiol 138(1): 341-351. https://doi.org/10.1104/pp.104.059147

34. Ito Y, Katsura K, Maruyama K, Taji T, Kobayashi M, Seki M, Shinozaki K, Yamaguchi-Shinozaki K (2006) Functional analysis of rice DREB1/CBF-type transcription factors involved in cold-responsive gene expression in transgenic rice. Plant Cell Physiol 47(1):141-153. https://doi.org/10.1093/pcp/pci230

35. Ali Q, Elahi M, Hussain B, Hussain N, Ali F, Elahi F (2011) Genetic improvement of maize (Zea mays L.) against drought stress: an overview. Agric Sci Res J 1:228-237

36. Sreenu P, Sateesh Kumar P, Reddy MK, Sailaja D, Pavan Kumar G (2016) Resourceful and high efficiency Agrobacterium mediated transformation of maize (Zea mays L.) using coleoptilar nodal explants. Int J Curr Res Biosci Plantbiol 3(12):1-9. https://doi.org/10.20546/ijcrbp.2016.312.001

37. Li Q, Li Y, Li C, Yu X (2012) Enhanced ascorbic acid accumulation through overexpression of dehydroascorbate reductase confers tolerance to methyl viologen and salt stresses in tomato. Czech J Genet Plant Breed 48(2):74-86. https://doi.org/10.17221/100/2011-CJGPB

38. Le Martret B, Poage M, Shiel K, Nugent GD, Dix PJ (2011) Tobacco chloroplast transformants expressing genes encoding dehydroascorbate reductase, glutathione reductase, and glutathione-S-transferase, exhibit altered anti-oxidant metabolism and improved abiotic stress tolerance. Plant biotechnol J 9(6):661-673. https://doi.org/10.1111/j.1467-7652.2011.00611.x

39. Eltelib HA, Fujikawa Y, Esaka M (2012) Overexpression of the acerola (Malpighia glabra) monodehydroascorbate reductase gene in transgenic tobacco plants results in increased ascorbate levels and enhanced tolerance to salt stress. S Afr J Bot 78:295-301. https://doi.org/10.1016/j.sajb.2011.08. 005

40. Grando MF, Varnier ML, de Silva MR, Emydgio BM, Pereira LR, Suzin M (2013) Immature tassels as alternative explants in somatic embryogenesis and plant regeneration in south Brazilian maize genotypes. Acta Scientiarum Agron 35(1):39-47. https://doi.org/10.4025/actasciagron.v35i1.15545

41. O'Connor-Sanchez A, Cabrera-Ponce J, Valdez-Melara M, Tellez-Rodriguez P, Pons-Hernandez J, Herrera-Estrella L (2002) Transgenic maize plants of tropical and subtropical genotypes obtained from calluses containing organogenic and embryogenic-like structures derived from shoot tips. Plant Cell Rep 21(4):302-312. https://doi.org/10.1007/s00299-002-0502-8

42. Sairam RV, Parani M, Franklin G, Lifeng Z, Smith B, MacDougall J, Wilber C, Sheikhi H, Kashikar N, Meeker K, Al-Abed D, Berry K, Vierling R, Goldman SL (2003) Shoot meristem: an ideal explant for Zea mays L. transformation. Genome 46(2):323-329. https://doi.org/10.1139/g02-120
43. Al-Abed D, Rudrabhatla S, Talla R, Goldman S (2006) Split-seed: a new too for maize researchers. Planta 223(6):1355-1360. https://doi.org/10.1007/ s00425-006-0237-9

44. Mushke R, Yarra R, Bulle M (2016) Efficient in vitro direct shoot organogenesis from seedling derived split node explants of maize (Zea mays L.). J Genet Eng Biotechnol 14(1):49-53. https://doi.org/10.1016/j.jgeb.2 016.03.001

45. Pavan Kumar G, Sreenu P, Sridevi M, Reddy MK, Sateesh Kumar P (2018) Coleoptilar node - a season independent explant source for in vitro culture in maize (Zea mays L.). J Appl Biol Biotechnol 6:20-28. https://doi.org/10. 7324/JABB.2018.60304

46. Torney F, Moeller L, Scarpa A, Wang K (2007) Genetic engineering approaches to improve bioethanol production from maize. Cur Opin Biotechnol 18(3):193-199. https://doi.org/10.1016/j.copbio.2007.03.006

47. Vega JM, Yu W, Kennon AR, Chen X, Zhang ZJ (2008) Improvement of Agrobacterium-mediated transformation in Hi-II maize (Zea mays L.) using standard binary vectors. Plant Cell Rep 27(2):297-305. https://doi.org/10.1 007/s00299-007-0463-z

48. Abhishek A, Karjagi CG, Nath R, Bhardwaj M, Ramteke PW, Kumar P, Dass S, Kumar RS (2014) Differential effect of immature embryo's age and genotypes on embryogenic type II callus production and whole plant regeneration in tropical maize inbred lines (Zea mays L.). Ind J Gen Plant Breed 74(3):317-324. https://doi.org/10.5958/0975-6906.2014.00849.9

49. Du D, Jin R, Guo J, Zhang F (2019) Infection of embryonic callus with Agrobacterium enables high-speed transformation of maize. Int J Mol Sci 20(2):279. https://doi.org/10.3390/ijms20020279

50. Kim HA, Utomo SD, Kwon SY, Min SR, Kim JS, Yoo HS, Choi PS (2009) The development of herbicide-resistant maize: stable Agrobacterium-mediated transformation of maize using explants of type II embryogenic calli. Plant Biotechnol Rep 3(4):277-283. https://doi.org/10.1007/s11816-009-0099-2

51. Ombori O, Muoma JVO, Machuka J (2013) Agrobacterium-mediated genetic transformation of selected tropical inbred and hybrid maize (Zea mays L.) lines. Plant Cell Tis Org Cult 113(1):11-23. https://doi.org/10.1007/s11240012-0247-1

52. Sreenu P, Sridevi M, Sateesh Kumar P, Reddy MK, Sailaja D, Pavan Kumar G (2016) Optimization of some influential factors in maize genetic transformation through microprojectile bombardment. Int J Rec Sci Res 7: 10517-10522. https://doi.org/10.24327/ijrsr

53. Saker MM, Abdallah SS, Youssef SS, Moursy HA, El-Sharkawy AM (2006) Development of transformation system for some Egyptian rice genotypes using particle bombardment. Am Euras J Agric Environ Sci 1:7-13

54. Tadesse $Y$, Sagi L, Swennen R, Jacobs M (2003) Optimization of transformation conditions and production of transgenic sorghum (Sorghum bicolor) via microparticle bombardment. Plant Cell Tis Org Cult 75(1):1-18. https://doi.org/10.1023/A:1024664817800

55. Abbas Z, Ali S, Din JU, Ali GM (2017) In vitro plant regeneration from coleoptilar node of maize seedling: a new tool to bioengineer the maize rapidly. Sarhad J Agric 33(4):606-614. https://doi.org/10.17582/journal.sja/2 017/33.4.606.614

56. Wu H, Sparks C, Amoah B, Jones HD (2003) Factors influencing successful Agrobacterium-mediated genetic transformation of wheat. Plant Cell Rep 21(7):659-668. https://doi.org/10.1007/s00299-002-0564-7

57. Takavar S, Rahnama H, Rahimian H, Kazemitabar K (2010) Agrobacteriummediated transformation of maize (Zea mays L.). J Sci Islam Repub Iran 21 : $21-29$

\section{Publisher's Note}

Springer Nature remains neutral with regard to jurisdictional claims in published maps and institutional affiliations. 